\title{
Entre o neodesenvolvimentismo e a ortodoxia: contradições da política econômica no governo Dilma Rousseff
}

DOI: 10.15175/1984-2503-202113305

\author{
Sydenham Lourenço Neto*
}

\begin{abstract}
Resumo
O artigo pretende expor as razões do fracasso da estratégia da política econômica do governo de Dilma Roussef, especialmente o primeiro, que buscou implementar estratégias desenvolvimentistas, como o "Plano Brasil Maior", que visava manter taxas elevadas de crescimento do PIB e, ao mesmo tempo, manter a política de redução das desigualdades sociais. Nossa hipótese é que fatores econômicos nacionais e internacionais determinaram o fracasso da estratégia. Contudo, também foi relevante a falta de consistência da política econômica adotada que buscou usar ferramentas desenvolvimentistas de forma muito tímida e as abandonou quando surgiram pressões fiscais e inflacionárias muito supervalorizadas pelos representantes do capital financeiro. O governo Dilma ensaiou desafiar os interesses do capital financeiro, mas, recuou rapidamente abandonado as políticas baseadas no crescimento do investimento público e no aumento do consumo. Assim, não logrou os benefícios do desenvolvimento acelerado nem conseguiu a estabilidade monetária tão louvada pelos setores financeiros e seus associados no interior do empresariado
\end{abstract}

Palavras-chave: neodesenvolvimentismo; governo Dilma Rousseff; crise econômica.

\section{Entre el neodesarrollismo y la ortodoxia: la política económica en el gobierno de Dilma Rousseff}

\section{Resumen}

El artículo pretende exponer las razones del fracaso de la política económica del gobierno de Dilma Rousseff, que buscaba implementar estrategias desarrollistas, como el Plano Brasil Maior, un programa que tenía como objetivo mantener un alto índice de crecimiento del PIB y, al mismo tiempo, continuar con la política de reducción de las desigualdades sociales. Nuestra hipótesis es que hubo diversos factores económicos nacionales e internacionales que determinaron el fracaso de la estrategia. Sin embargo, también fue relevante la falta de consistencia de la política económica adoptada, que buscó utilizar herramientas desarrollistas de manera muy tímida y las abandonó cuando surgieron presiones fiscales e inflacionarias, altamente sobrevaloradas por los representantes del capital financiero. El gobierno de Dilma trató de desafiar los intereses del capital financiero, pero rápidamente se echó atrás y abandonó las políticas basadas en el crecimiento de la inversión pública y el aumento del consumo. Así, no logró los beneficios de un desarrollo acelerado ni consiguió la estabilidad monetaria tan alabada por los sectores financieros y sus asociados dentro de la comunidad empresarial.

\footnotetext{
*Professor Associado da Universidade do Estado do Rio de Janeiro e membro do corpo docente do Mestrado em História Social do Território (PPGHS-UERJ). Graduado em História pela Universidade Federal Fluminense (1991), mestrado em Ciência Política (Ciência Política e Sociologia) pelo Instituto Universitário de Pesquisas do Rio de Janeiro (1994) e doutorado em Ciência Política (Ciência Política e Sociologia) pelo Instituto Universitário de Pesquisas do Rio de Janeiro (2001). E-mail: slneto@hotmail.com.

(9) http://lattes.cnpq.br/9691041473291952. 는 https://orcid.org/0000-0003-1015-4831
} 
Palabras clave: neodesarrollismo; gobierno de Dilma Rousseff; crisis económica.

\title{
Between Neo-developmentalism and orthodoxy: Economic policy under Dilma Rousseff's government
}

\begin{abstract}
The following article aims to expose the reasons behind the failure of Dilma Rousseff's government's economic policy, seeking as it did to implement developmental strategies such as the Plano Brasil Maior [Greater Brazil Plan], which aimed to keep GDP growth high while maintaining the policy to reduce social inequality. Our hypothesis is that although national and international economic factors determined the strategy's failure, the lack of consistency in the economic policy adopted was also a factor, which sought to use developmental tools in a highly conservative manner and abandoned them in the face of emerging fiscal and inflationary pressures, which were highly overvalued by the representatives of financial capital. Although Rousseff's government attempted to challenge the interests of financial capital, it swiftly backed down and abandoned policies based on the growth of public investment and increased consumption. It therefore failed to achieve the benefits of accelerated development and the monetary stability so lauded by the financial sectors and their associates within the business sector.
\end{abstract}

Keywords: Neo-developmentalism; Dilma Rousseff's government; economic crisis.

\section{Entre néodéveloppementisme et orthodoxie: la politique économique du gouvernement de Dilma Rousseff}

\section{Résumé}

Cet article entend exposer les raisons de l'échec de la politique économique du gouvernement de Dilma Rousseff, qui avait essayé de mettre en œuvre des stratégies développementistes, à l'instar du programme "Plano Brasil Maior », visant le maintien de taux élevés de croissance du PIB, et de poursuivre en parallèle une politique de réduction des inégalités sociales. Notre hypothèse est que des facteurs économiques nationaux et internationaux ont déterminé l'échec de cette stratégie. Tout aussi pertinent a néanmoins été le manque de consistance de la politique économique adoptée, en ce qu'elle a cherché à faire un usage fort timide d'outils développementistes avant de les abandonner dès qu'apparurent les premières pressions fiscales et inflationnistes, au demeurant très exagérées par les représentants du capital financier. Le gouvernement de Dilma Rousseff tenta donc de défier les intérêts du capital financier, mais recula très rapidement en abandonnant les politiques basées sur la croissance de l'investissement public et l'augmentation de la consommation. C'est ainsi qu'il n'obtint ni les bénéfices d'un développement accéléré ni la stabilité monétaire que souhaitait si ardemment les secteurs financiers et leurs alliés au sein du patronat.

Mots-clés : Néodéveloppementisme ; gouvernement de Dilma Rousseff ; crise économique.

\section{在新发展主义与自由主义之间：迪尔玛·罗赛芙政府的经济政策}

\section{摘要}

这篇文章旨在分析迪尔玛.罗赛芙政府的经济政策失败的原因。该政府试图执行发展战略，实施保持高 GDP 增 长率的 “巴西计划”，并在发展经济的同时，增加社会福利开支以便减少社会不平等问题。我们认为，巴西国 内和国际经济因素导致了罗赛芙政府经济战略的失败。另外，他们的失败也跟他们所采取的经济政策缺之一致 性有关，他们追求经济发展目标时，所使用的方式过于谨慎与胆怯，一旦出现了财政和通胀压力，马上就放弃 了它们。事实上，这些压力被金融资本的代表们高估。迪尔玛·罗赛芙政府试图挑战金融资本的利益，但因为 它们过于强大，很快就做出让步，放弃了增加公共投资，促进消费增长的政策。因此，它既没有实现经济加速 发展，也没有实现金融界和工商界所推崇的货币稳定。 
关键词：新发展主义；迪尔玛·罗赛芙政府；经济危机。

Dilma Roussef assumiu o governo do Brasil, em 2011, herdando um grande crescimento do PIB que prometeu manter, o Brasil havia conseguido um crescimento de $7,5 \%$ do PIB, em 2010. Seu primeiro ano de governo conseguiu manter um crescimento muito próximo da média mundial, $2,7 \%$ no Brasil contra 4,4 no mundo, como é reconhecido até por alguns dos seus críticos (BOLLE, 2016, p. 29). O crescimento de 2011 consolidou o Brasil como a sétima economia do mundo (BRASIL..., 2014), no entanto, na comparação com o ano de 2010 estávamos assistindo uma desaceleração, o que foi suficiente para gerar cobranças de setores do empresariado, dos sindicatos e também da mídia especializada (SKAF; HENRIQUE; SILVA, 2011).

O governo Dilma Rousseff reagiu às críticas prometendo publicamente um crescimento mais elevado do PIB. O diagnóstico de que o crescimento estava sendo abaixo do esperado, embora ainda próximo da média mundial, somado com as pressões políticas sobre o governo provocaram o lançamento de um plano de aceleração do desenvolvimento intitulado "Plano Brasil Maior", no segundo semestre de 2011.

O objetivo explícito do Plano Brasil Maior era acelerar o crescimento econômico. Em um dos documentos oficiais do governo explicando o plano é dito que ele "engloba medidas tributáveis, financiamento de comércio exterior, incentivo ao setor de informação e comunicações, medidas creditícias e criação do novo regime automotivo (BRASIL, 2012). O Secretário de Política Econômica do Ministério da Economia, Márcio Holland, em entrevista para o jornal Valor Econômico, afirmou que o plano seria capaz de criar uma nova matriz econômica para o Brasil (ROMERO, 2012). A denominação é certamente pretensiosa, mas, logo foi abraçada por jornalista e economistas liberais que visavam denunciar o intervencionismo do governo Dilma. Na essência, a pretensa nova matriz significou a ampliação de alguns mecanismos que o Governo Lula utilizou para responder a crise de 2008 e o baixo crescimento do país, em 2009, colocando a economia em marcha forçada, isto é, respondendo à crise recessiva mundial com políticas expansionistas, principalmente políticas de crédito e investimentos.

Apesar do Plano Brasil Maior ter sido apresentado como se fosse um novo Plano Nacional de Desenvolvimento, ou talvez um novo Plano de Metas, as medidas efetivas que foram implementadas podem ser resumidas em alguns poucos itens e todas sofreram de falta de consistência. Medidas muito tímidas e que foram abandonadas antes que pudessem resultar em qualquer tipo de transformação mais estrutural na economia 
brasileira. Na prática, a nova matriz econômica, significou uma tentativa de redução dos juros praticados na economia, tanto da taxa Selic quanto dos juros reais para investidores e consumidores, a desvalorização do real, desonerações de impostos e tributos, principalmente os incidentes sobre a folha trabalhista, e o represamento das tarifas de energia elétrica. São esses os aspectos que detalharemos nos próximos parágrafos.

\section{Enfrentando o mercado financeiro}

A redução da Selic só começou a ser realizada em meados de 2011, mas, logo se verificou que a redução em alguns poucos pontos percentuais da Selic não provocava reduções equivalentes dos juros reais incidentes nos empréstimos para investimentos e consumo. O Banco Central percebeu a ineficiência da simples redução da Selic e a partir de fevereiro de 2012 passou a orientar os bancos públicos a reduzirem os juros reais de seus empréstimos, forçando através da concorrência, que os bancos privados fizessem o mesmo. O objetivo era reduzir a escandalosamente alta taxa média de spread praticada pelos bancos brasileiros. O spread é a diferença entre o custo de captação de dinheiro e o lucro obtido com os juros cobrados sobre este mesmo dinheiro. Esta política, provavelmente, foi uma das que mais gerou oposição por parte dos setores ligados ao capital financeiro. Neste ponto concordamos com André Singer (2018, p. 40), Dilma estava cutucando onça com bases curtas e discordamos de avaliações que exageram o alcance das medidas classificando-as como uma espécie de desafio estrutural ao poder do capital financeiro brasileiro (BASTOS, 2017, p. 8).

\section{O problema da supervalorização cambial}

A desvalorização do real, buscando estimular as exportações e inibir as importações foi muito tímida. Ao longo dos dois governos Lula o real se valorizou cerca de $108 \%$ (SCRIVANO, 2010). Em 2011, o dólar se manteve na faixa de $R \$ 1,60$, subindo para cerca de $\mathrm{R} \$ 2,20$ no final de 2013. Isto é, mesmo com a autoproclamada política de desvalorização do real, a desvalorização de fato não atingiu o patamar de $30 \%$, ficando muito longe, portanto, de recuperar os níveis de 2003, que, segundo alguns analistas, já eram altos. Não compartilhamos da tese defendida tantas vezes por Bresser Pereira, segundo a qual o câmbio sobrevalorizado é o principal responsável por nossa 
desindustrialização e baixo crescimento econômico nos últimos anos (NASSIF; BRESSER PEREIRA; FEIJÓ, 2018), contudo, o câmbio muito apreciado certamente é um problema que foi timidamente enfrentado pelo governo Dilma. Na realidade, o real só se desvalorizou fortemente a partir de 2015, quando o país mergulhou em forte recessão, e até agora esta desvalorização não começou a estimular um processo de reindustrialização.

A timidez da política de desvalorização do real por parte do governo Dilma explicase, principalmente, pelo fato de que o real valorizado é um mecanismo de controle da inflação. O real valorizado garante que nossos empresários têm que enfrentar a concorrência de produtos estrangeiros que chegam ao mercado brasileiro com preços relativos competitivos e, portanto, não podem praticar preços que tenham embutido taxas de lucratividades exageradas, sob pena de perder o mercado consumidor. Desde a primeira vez em que funcionários do governo começaram a falar nas estratégias da nova política econômica, economistas, políticos e jornalistas liberais atacaram o modelo afirmando que ele seria complacente com a inflação, e de fato, a inflação apresentou uma relativa tendência de alta durante o primeiro governo Dilma, embora nunca tenha ultrapassado o centro da meta estabelecido pelo Banco Central, que era de 6,5\%.

Seja por conta das críticas, seja por conta de convicções pessoais dos membros do governo Dilma, o fato é que a política monetária manteve uma constante preocupação com o aumento da inflação, o que certamente inibiu políticas de desvalorização do real. Pior que isto, no início do segundo governo Dilma o controle da inflação passou a ser a preocupação central da política econômica. Ironicamente, foi justamente em 2015 que a inflação brasileira alcançou o patamar mais alto registrado desde os anos 1990.

\section{O gerenciamento político das tarifas de energia}

Em setembro de 2012, o governo editou a medida provisória $\mathrm{n}^{\circ} 579$, com o principal objetivo de reduzir as tarifas de energia elétrica em $20 \%$. O principal mecanismo utilizado para provocar o barateamento das tarifas foi oferecer uma antecipação da renovação das concessões desde que as concessionárias se comprometessem a promover uma redução de sua lucratividade que, em alguns casos, podia chegar a 70\%. Contudo, não se exigia sacrifício apenas das empresas privadas, os governos estaduais também deveriam reduzir a cobrança de ICMS sobre o consumo de energia elétrica. É bom lembrar que os governos estaduais de São Paulo e Minas Gerais não aceitaram participar do acordo e mantiveram 
os impostos inalterados, apesar da promessa do governo federal de compensar as perdas estaduais com transferências orçamentárias.

A medida provisória foi aprovada pelo Senado, em dezembro de 2012, mas, provocou forte reação do mercado desde o momento em que foi editada. O governo foi acusado de praticar o intervencionismo, trazendo insegurança jurídica para as concessionárias e reduzindo o valor de mercado das mesmas (MEDIDA..., 2012). Certamente, parte da oposição à medida partiu do capital financeiro, especialmente alguns fundos de investimento, que detinham grande quantidade de ações das empresas de energia elétrica. Governadores de oposição também protestaram, alegando dificuldades orçamentárias que seriam pioradas com a redução dos impostos.

Do ponto de vista do governo, a medida provisória desempenhava uma dupla função, estimulava o investimento em setores de alto consumo de energia e contribuía para reduzir a inflação. Em breve, procuraremos demonstrar porque esta e outras medidas de incentivo descritas aqui tiveram pouco resultado prático, por enquanto vale salientar que mesmo o positivo efeito sobre a inflação se transformou numa armadilha. No início de 2015, o governo Dilma autorizou o primeiro de muitos aumentos no preço da energia elétrica que aconteceram naquele ano, que chegaram a somar, segundo o Banco Central (BRASIL, 2016), 49\% de aumento, o que teria impactado a inflação do ano em $1 / 3$. Isto é, os aumentos das tarifas de energia elétrica sozinhos foram responsáveis por quase $4 \%$ da inflação que naquele ano somou 10,67\%. No final, as concessionárias de energia conseguiram obter a renovação antecipada de suas concessões e recuperaram em pouco tempo toda a lucratividade que tinham perdido ao longo de 2013 e 2014.

\section{A desoneração de impostos como estratégia para aumentar a lucratividade privada}

Chegamos agora naquilo que talvez tenha sido a espinha dorsal da Nova Matriz Econômica. Na realidade, não foi uma grande inovação, o governo Lula resolveu responder aos problemas gerados pela crise mundial de 2008 oferecendo reduções temporárias de impostos para setores chaves, especialmente o setor automobilístico. Mas, o governo Dilma ampliou muito a escala do uso da estratégia de desonerações. Em agosto de 2011, o governo Dilma anunciou o Plano Brasil Maior, que em seu próprio nome explicitava o desejo de manter um forte crescimento do PIB, o plano previa a redução do IPI (Imposto sobre 
produtos industrializados) para vários setores, como o automotivo e a construção civil, incentivos tributários para exportadores e desoneração da folha de pagamento.

Como o PIB continuou apresentando um crescimento baixo, na avaliação do próprio governo, a política de desoneração foi sendo ampliada. A redução do IPI, que a princípio deveria durar apenas um ano foi sendo prorrogada até 2014, e de certa forma foi responsável por criar uma bolha, porque quando foi anunciado que não haveria mais a prorrogação, o consumo dos bens isentos, como os automóveis e caminhões, disparou e após o fim da desoneração caiu expressivamente.

Foi na desoneração da folha de pagamento, contudo, que o governo Dilma parece ter apostado suas maiores esperanças. Em 2011, quando foi lançada, ela só atingia quatro setores e seria temporária. Em 2014, a política já atingia 54 setores e foi transformada em permanente, em junho do ano citado. Essencialmente a desoneração da folha de pagamento significava que o empresariado deixava de pagar $20 \%$ sobre a folha salarial e passava a pagar menos de $2 \%$ sobre o faturamento. Parece se tratar de uma política que estimula o emprego, porque a contratação de novos funcionários não implica, necessariamente, no aumento da carga tributária das empresas. De fato, a medida poderia estimular o emprego, contudo ela foi tomada num momento em que o desemprego era baixo e os empresários não estavam contratando por considerarem que o salário estava sobrevalorizado e pressionava a lucratividade, de modo que a desoneração da folha de pagamentos não seria suficiente para convencer o empresariado a fazer novas contratações. Tratou-se de uma medida relativamente certa no momento errado.

Havia um lado positivo na desoneração da folha de pagamento, mas, que teve pouco efeito por conta do momento em que foi implementada. Por outro lado, houve uma consequência bastante negativa da desoneração: a criação de um déficit na previdência. Cabe mencionar que o debate atual sobre a Reforma da Previdência não leva em conta que o governo abriu mão de receitas previdenciárias por conta da política de desoneração da folha de pagamentos.

A estratégia de desonerações não foi suficiente para estimular novos investimentos privados por parte dos empresários privados beneficiados e ainda criou uma enorme pressão política por conta das parcelas do empresariado que não foram beneficiados. Escolher, por exemplo, 54 setores que passariam a gastar menos com a folha de pagamentos e deixar centenas de fora do benefício, acabou gerando frustração e ressentimento em amplas camadas do empresariado. 
As políticas da Nova Matriz Econômica mostraram poucos resultados, mesmo assim o governo Dilma continuou aumentado a aposta, especialmente na política de desoneração da folha de pagamento até que, em 2015, resolveu dar um "cavalo de pau em Boeing" e abandonou todos os princípios que antes eram defendidos, inclusive aqueles que vinham apresentando resultados relativamente positivos. Na próxima seção vamos discutir as razões do fracasso da Nova Matriz Econômica.

\section{Os custos do fracasso das tímidas medidas desenvolvimentistas}

Num trabalho publicado nos anos 1970, Albert Fishlow (1972), definiu o crescimento econômico do Brasil como seguindo um padrão de Stop and Go. Isto é, alguns anos de crescimento provocavam alguns anos de recessão. O crescimento não se mostra sustentável. De fato, se olharmos o crescimento do PIB, desde os anos 1930, jamais encontramos uma sequência de mais que sete anos de crescimento acima da média mundial. Fishlow, contudo, não avança muito na explicação do fenômeno. Nossa tese é que o próprio crescimento acaba tornando mais evidente os pontos de estrangulamento estruturais, mas, os governos (mesmo os autoritários), buscando manter a popularidade alcançada com o crescimento, apostam em estratégias de curto prazo, que não resolvem os problemas estruturais, ao contrário, tornam eles ainda mais evidentes.

Uma das questões mais interessantes sobre o lançamento da autointitulada Nova Matriz Econômica é que não faltou apoio político para a mesma. Ao contrário, ao lançá-la o governo Dilma parecia estar atendendo aos objetivos de uma ampla gama de demandas que atendiam aos interesses das principais centrais sindicais de trabalhadores, mas, também de empresários. Tanto que, uma das principais analistas deste processo prefere chamar a Nova Matriz Econômica de Agenda FIESP (CARVALHO, 2018).

De fato, o Plano Brasil Maior, em vários aspectos atendia demandas que foram explicitadas em um artigo publicado na Folha de São Paulo, em maio de 2011, intitulado "Um acordo pela indústria brasileira" (SKAF; HENRIQUE; SILVA, 2011), e que foi assinado por Paulo Skaf (presidente da FIESP), Arthur Henrique (presidente da CUT) e Paulo Pereira da Silva (presidente da Força Sindical).O artigo apresentava, portanto, posições que eram consensuais para as duas maiores centrais sindicais de trabalhadores, mas, também para a principal federação de industriais do país. O diagnóstico apresentado no artigo citado apontava que mesmo o recente crescimento do país não estava sendo capaz de evitar 
nossa desindustrialização e a reprimarização da economia, com fortes consequências para nossa balança comercial. Mas, os signatários do artigo foram além, e dias depois enviaram um documento oficial para a presidente Dilma formalizando suas propostas para a recuperação da economia, que estavam centradas principalmente na desvalorização do real,na queda dos juros e na desoneração da folha de pagamentos.

Já vimos que todas estas medidas foram pelo menos tentadas, mas, seus resultados reais foram pífios. A produção industrial total, que havia crescido 2,7\% em 2010 (ainda assim bem abaixo do crescimento total do PIB), caiu 0.9\% em 2011 e caiu 3.7\%, em 2012. No mesmo período a capacidade ociosa da indústria subiu de 15\% para 20\% (CARVALHO, 2018, p. 58). Mas, talvez o dado mais importante seja a constatação de que a desindustrialização continuou, em 2011, a indústria respondia por 13,9\%, caindo para 10,9\%, em 2014, o menor índice desde 1947.

O fracasso da Nova Matriz Econômica, ou Agenda FIESP, ou simplesmente Plano Brasil Maior, é inegável, na medida em que a desindustrialização continuou acelerada e o PIB não cresceu o esperado segundo as próprias previsões do governo. Para 2013, por exemplo, o crescimento projetado foi de $3,3 \%$ e o crescimento real verificado foi de $2,5 \%$. O fracasso do Plano Maior certamente foi determinante para o rompimento da aliança política com a FIESP e até mesmo com algumas centrais sindicais. FIESP e Força Sindical trabalharam contra a reeleição de Dilma, em 2014, e depois formaram parte da linha de frente do movimento a favor do golpe jurídico e parlamentar de 2016.

Mas, por que o Plano Brasil Maior fracassou de forma tão inegável? Dois autores, que já citamos neste trabalho divergem sobre as causas, para Laura Carvalho (2018) o plano era muito tímido e exageradamente dependente dos investimentos privados, para André Singer (2018) a tentativa de manter o crescimento acelerado, verificado em 2010 , em conjunto com políticas que visavam reduzir a desigualdade foi ousada demais, considerando as frágeis bases políticas do governo Dilma. Isto é, para um autor houve timidez para outro houve excesso de ousadia, para um autor o problema foi fundamentalmente econômico para o outro foi principalmente político. Nossa perspectiva está mais próxima da defendida por Laura Carvalho, contudo, acreditamos que a tese da autora também precisa passar por algumas ponderações. Se é verdade que em alguns aspectos houve excesso de moderação ou de timidez, cabe perguntar se era realista prometer um crescimento acelerado diante da conjuntura econômica nacional e internacional verificada entre 2011 e 2013, e se ao fazer esta promessa o governo não acabou gerando uma frustração que alimentou forças políticas 
de oposição. Porque, de fato, não é possível separar completamente a questão econômica da questão política. O fracasso econômico do governo Dilma foi o principal combustível para o seu fracasso político.

Era realista prometer crescimento elevado da economia nos anos de 2012 e 2013 ? Fatores nacionais e internacionais indicam que dificilmente era realista. Dentre os fatores nacionais se destaca a questão do endividamento dos consumidores, que pode explicar porque mesmo com a redução do IPI, o consumo dos produtos beneficiados não aumentou consideravelmente, na realidade só se verificou um crescimento expressivo quando foi anunciado que a política de redução de impostos seria encerrada. Entre 2013 e 2014, o endividamento das famílias brasileiras alcançou cerca de $25 \%$ do PIB, algo muito acima do padrão histórico brasileiro. Dez anos antes, por exemplo o endividamento pouco ultrapassava $10 \%$ do PIB (GARBER et al., 2018).

Certamente, o grande endividamento das famílias durante os governos do PT foi gerado pela política de expansão do crédito e redução relativa dos juros, e isto foi fundamental para a obtenção de um forte crescimento médio do PIB entre 2007 e 2010, período que Laura Carvalho chama de milagrinho econômico. Contudo, manter a estratégia, num cenário em que as famílias já estão muito endividadas não gera os mesmos resultados anteriormente verificados. Estimular o crédito, reduzir juros e até mesmo manter a política de valorização do salário-mínimo não estimula o consumo, porque as famílias já estão endividadas demais para contrair novas dívidas. Na realidade, o melhor que se poderia fazer naquele momento seria uma política de crédito barato voltada especificamente para a renegociação e redução das dívidas existentes. Só após a redução do endividamento geral das famílias se poderia pensar em um novo ciclo de investimento baseado no consumo interno.

O consumo das famílias não subiu o esperado após o lançamento do Plano Brasil Maior, na realidade, em 2012, teve o pior crescimento (4,1\%), desde 2004 (TABAK, 2012). O consumo familiar continuou mantendo taxas modestas de crescimento até que, em 2015, caiu mais de $4 \%$. Se o consumo não subiu, por que os empresários, especialmente os industriais, que já experimentavam capacidade ociosa, deveriam investir? Do ponto de vista do empresariado, eles continuavam convivendo com uma taxa de câmbio que não garantia proteção contra a concorrência externa, vimos que a desvalorização do real foi muito tímida, sabiam que o governo manteria a política de valorização do salário-mínimo o que em conjunto com taxas médias de desemprego relativamente baixas aumentavam o custo da 
mão-de-obra e sabiam que as projeções não indicavam uma explosão do consumo interno que justificasse novos investimentos.

Não cabe, portanto, requentar velhas teses do nacional desenvolvimentismo e dizer que o empresariado não aumentou os investimentos porque sofreu de algum tipo de falsa consciência, falsa percepção dos seus reais interesses, e por isto não percebeu as oportunidades apesar de todas as políticas favoráveis implementadas pelo governo (SINGER, 2018). O empresariado nacional tinha sólidos motivos para não aumentar seus investimentos, e é mais provável que tenha capitalizado as desonerações para aumentar a sua margem de lucro através de investimentos financeiros, até como uma tentativa de resolver suas dificuldades contábeis claramente demonstradas no estudo da Fiesp que analisaremos a seguir.

Se o cenário nacional não estimulava novos investimentos, muito menos o cenário internacional. A crise de 2008 provocou uma primeira derrubada nos preços das commodities, contudo, basicamente porque o crescimento da China continuou num ritmo elevado, houve uma relativa recuperação dos preços entre 2011 e 2012, porém, a partir de 2013, e principalmente em 2014, o preço das commodities caiu para níveis abaixo dos que eram praticados em 2007. A maioria dos países em que as commodities têm um peso importante na economia, como o Canadá e a Austrália, responderam à queda nos preços das commodities desvalorizando sua moeda (KRUGMAN, 2018a). Mas, já vimos que o governo Dilma praticou uma desvalorização excessivamente tímida, que não recompensou minimamente a valorização que foi verificada durante os dois governos Lula. Com a perspectiva da queda dos preços e sem a garantia de proteção cambial nem mesmo os produtores de commodities tinham incentivos para aumentar os investimentos.

\section{A baixa lucratividade e a dependência}

Em junho de 2018, o Instituto de Estudos para o Desenvolvimento Industrial (IEDI) da FIESP começou a divulgar um amplo estudo sobre o desempenho das empresas brasileiras no período entre 2007 e 2017. No total foram pesquisadas 293 empresas, agrupadas em três macros setores, indústria, comércio e serviços (IEDI, 2018). O estudo do IEDI não é relevante apenas pelos dados que apresenta, mas, também por ter sido produzido pela principal associação de industriais do Brasil, portanto, seus números circularam entre o grande empresariado brasileiro e podem ter influenciado decisões de investimentos. 
O estudo do IEDI mostra que a situação das empresas brasileiras já provocava alguma preocupação desde 2011. A partir desde ano, verifica-se um aumento dos custos da produção, especialmente custos com a mão de obra, que dificultava a competitividade da indústria brasileira, justamente num período em que a China estava ampliando suas exportações para o Brasil, aproveitando-se de nossa moeda sobrevalorizada. ${ }^{1} \mathrm{Na}$ média da indústria geral, o custo de salários, que era de $8,9 \%$ do valor da produção em 2007 , subiu para 10,1\% em 2011, alcançando 10,8\% em 2015.

Diante do aumento dos custos e da baixa expectativa de um considerável aumento da demanda interna e externa o que se verificou foi uma acentuada redução dos investimentos, a partir de 2013. Segundo o estudo da FIESP, a indústria passou a adotar uma postura defensiva, vendendo ativos e buscando investimentos de retorno de curto prazo, especialmente investimentos financeiros. Enquanto em 2014, apenas 4\% das receitas das indústrias tinham origem em investimentos financeiros, em 2014, o índice praticamente dobrou, atingindo 7,3\%. Sabemos que, no final de 2013, o governo Dilma reverteu a política de redução da taxa Selic, sinalizando para o mercado que investimentos financeiros passariam a ser mais rentáveis. Portanto, ainda que buscasse o aumento do $\mathrm{PIB}$, na prática o governo incentivou um movimento de redução dos investimentos produtivos e o aumento dos investimentos financeiros. A indústria respondeu ao estímulo de maneira bastante racional.

A lucratividade obtida com investimentos financeiros, contudo, não foi de forma nenhuma suficiente para garantir uma rentabilidade positiva para as empresas nãofinanceiras brasileiras. Segundo o estudo da FIESP, em 2014, as empresas brasileiras estavam fortemente endividadas, inclusive em moeda estrangeira, de modo que a desvalorização do real verificada, a partir de 2014, teve efeitos ambíguos. Se por um lado, trouxe certa proteção contra a competição estrangeira, por outro lado agravou o problema do endividamento. Para a maioria das empresas estudadas, em 2015, o lucro foi suficiente apenas para pagar as chamadas despesas contratuais, custo do trabalho, dívidas e impostos, não deixando nenhuma margem para novos investimentos.

O estudo constatou que, após 2011, a retração dos investimentos das empresas se tornou praticamente uma constante, tendo como líder o setor industrial seguido dos demais setores, serviços e comércio. O processo ganha expressão às vésperas da recessão de 2015

1 O Estudo da FIESP não cita explicitamente os dados, mas, dados do Ministério da Economia indicam que em 2014 as importações chinesas para o Brasil atingiram o recorde de mais de 38 bilhões de dólares (BRASIL, 2020). 
e se estende até 2017. Se lembrarmos que ao mesmo tempo o investimento público também estava sendo reduzido é fácil entender as baixas taxas de crescimento do PIB no período.

\section{Conclusão}

Nossa conclusão só pode ser a de que os incentivos contidos no Plano Brasil Maior não enfrentavam os principais problemas da economia brasileira e dificilmente poderiam estimular o investimento privado. Contudo, ainda cabe perguntar, se era pouco realista esperar um aumento do investimento privado, por que não houve uma política baseada no investimento público?

Em 2011, quando foi lançado o Plano Brasil Maior a situação do orçamento público era uma das mais equilibradas da nossa história, o endividamento em moeda estrangeira era baixo, na realidade, tínhamos crédito com vários países. No mesmo ano, o superávit primário alcançou quase 129 bilhões de reais, o que permitiu que a dívida líquida caísse de $39,1 \%$ do PIB para 36,5\% (IZAGUIRRE, 2012). Isto é, o governo tinha uma folga para ampliar o investimento público, mas, o que ele resolveu fazer foi justamente o contrário. Usar o superávit para fornecer isenções e desonerações, o que diminuiu a arrecadação, enquanto diminuía o investimento público. Em 2010, o investimento público chegou ao auge, somando 4,6\% do PIB. Em 2014, foi reduzido para 3,94\%.

Os motivos que levaram o governo Dilma a apostar no investimento privado como motor do crescimento, mesmo diante de uma folga orçamentária que permitiria a manutenção da política de incremento do investimento público são mais políticos do que econômicos. Segundo Paul Krugman (2018b), o Brasil passou por uma crise típica de país desenvolvido, mas, respondeu como um país subdesenvolvido, excessivamente preocupado com a inflação e com a estabilidade monetária.

A excessiva preocupação monetarista impediu o governo Dilma de aprofundar a desvalorização cambial, a redução dos juros, a política de controle de preços chaves da economia, especialmente da energia, e pelo menos manter os mesmos níveis de investimentos públicos que foram praticados em 2010. Houve uma expectativa irreal de que estímulos poderiam provocar um aumento do investimento privado. Mas, as empresas privadas já estavam lidando com alto endividamento, inclusive em moeda estrangeira, baixo consumo das famílias (que também estavam muito endividadas) e aumento da concorrência estrangeira, especialmente da China. 
Se o empresariado brasileiro abandonou o apoio ao governo Dilma não foi por uma falsa consciência de seus interesses, mas, talvez por uma racionalidade míope. ${ }^{2}$ Diante de todas as dificuldades que o estudo da FIESP apontou, e nós tentamos esclarecer neste texto, os empresários parecem ter acreditado que a única forma de recuperar a competitividade seria reduzindo as despesas contratuais, isto é, dívidas, impostos e custos trabalhistas. Reduzir as dívidas, inclusive em moeda estrangeira, só seria possível num quadro de forte enfrentamento com o sistema financeiro, algo que o governo Dilma tentou timidamente e logo desistiu. Redução de carga tributária até ocorreu, mas, também de forma tímida e atingido alguns setores selecionados. Mas, especialmente no caso da redução dos custos trabalhistas o governo Dilma não se mostrou disposto a compactuar com a pauta do empresariado.

O empresariado precisava enfrentar o sistema financeiro, mas, estava muito comprometido com o mesmo. Vimos que uma das formas de defesa do empresariado foi justamente vender ativos para aumentar investimentos financeiros, portanto, o próprio setor se tornou sócio da lucratividade obtida com investimentos não-produtivos. O empresariado demandava redução da carga tributária, o que o governo Dilma de fato fez, mas, ao fazêlo, perdeu capacidade para manter o preço da energia, controlado. O empresariado demandava redução dos custos trabalhistas, inclusive da política de valorização do saláriomínimo, mas, não parece ter percebido que o a redução da renda do trabalhador significaria uma quase automática redução da demanda.

Na prática, falsa consciência e miopia podem parecer conceitos parecidos. Contudo, alegar falsa consciência significa dizer que o empresariado não sabe identificar os seus problemas reais. O estudo da FIESP indica que o empresariado estava lidando com problemas bastante reais, desde 2011, pelo menos. Miopia, ao contrário, significa que o empresariado conhece os seus problemas, mas tenta resolvê-los no curto prazo e sem uma percepção do resultado agregado da ação individual de cada empresário. No curto prazo todos querem reduzir seus custos, e isto é racional, contudo, o efeito agregado desta ação é reduzir a demanda agregada, o que acaba por prejudicar o conjunto do empresariado.

Um empresariado míope e um governo que fez um ensaio desenvolvimentista, mas, acabou ser rendendo às preocupações monetaristas pode ser um bom resumo das razões de nossa crise.

\footnotetext{
${ }^{2}$ Sobre a racionalidade míope ver Elster (1994, p. 60).
} 


\section{Referências}

BASTOS, Pedro Paulo Zahluth. Ascensão e crise do governo Dilma Rousseff e o golpe de 2016: poder estrutural, contradição e ideologia. Revista de Economia Contemporânea [online], 2017, v. 21, n. 2, e172129. Epub 21 dez. 2021.https://doi.org/10.1590/198055272129

BOLLE, Monica Baumgarten de. Como matar a borboleta-azul: uma crônica da era Dilma. Rio de Janeiro: Intrínseca, 2016.

BRASIL. Ministério da Fazenda. Plano Brasil Maior: Governo lança novas medidas para fortalecer indústria nacional: folha de pagamento é desonerada para mais onze setores. 5 abr. 2012. Disponível em: https://www.gov.br/receitafederal/ptbr/assuntos/noticias/2012/abril/plano-brasil-maior-governo-lanca-novas-medidas-parafortalecer-industria-nacional. Acesso em: 23 maio 2020.

BRASIL. Banco Central do Brasil. Aviso 1/2016-BCB: Carta Aberta de que trata o parágrafo único do art. $4^{\circ}$ do Decreto $n^{\circ} 3.088$, de 21 de junho de 1999. 8 jan. 2016. Disponível em: https://www.bcb.gov.br/content/controleinflacao/Documents/carta\%20aberta/carta2016.pdf . Acesso em: 5 abr. 2019.

BRASIL. Ministério da Economia. Secretaria Especial de Comércio Exterior e Assuntos Internacionais. Secretaria Especial de Produtividade e Competitividade. Balança Comercial Consolidada e Séries Históricas. 20 ago. 2020. Disponível em: https://www.gov.br/produtividade-e-comercio-exterior/pt-br/assuntos/comercio-

exterior/estatisticas/balanca-comercial-brasileira-acumulado-do-ano. Acesso em: 23 ago. 2020.

BRASIL é $7^{a}$ maior economia, e China deve passar EUA logo, diz Banco Mundial. UOL Economia, $30 \quad$ abr. 2014.2 Disponível em: https://economia.uol.com.br/noticias/redacao/2014/04/30/ranking-do-banco-mundial-trazbrasil-como-a-7-maior-economia-do-mundo.htm?cmpid=copiaecola. Acesso em: 20 jan. 2019.

CARVALHO, Laura. Valsa brasileira: do boom ao caos econômico. São Paulo: Todavia, 2018.

ELSTER, Jon. Peças e engrenagens das Ciências Sociais. Rio de Janeiro, RelumeDumará, 1994.

FISHLOW, Albert. Origins and consequences of import substitution in Brazil. In: DI MARCO, Luis Eugenio (Ed.). International Economics and Development: Essays in Honor of Raúl Prebisch. New York: Academic Press, 1972. p. 311-365. https://doi.org/10.1016/B978-0-12216450-7.50029-3

GARBER, Gabriel et al. Household Debt and Recession in Brazil. SSRN, Oct. 9, 2018. http://dx.doi.org/10.2139/ssrn.3263785 
INSTITUTO DE ESTUDOS PARA O DESENVOLVIMENTO INDUSTRIAL. A indústria brasileira no período 2007-2015: Estrutura setorial, custos, investimento e fragilidade financeira. $26 \quad$ jun. $2018 . \quad$ Disponível em: https://iedi.org.br/artigos/top/estudos_industria/20180626_estrutura_industrial.html. Acesso em: 22 jun. 2020.

IZAGUIRRE, Mônica. País cumpre meta fiscal e faz superávit primário de R $\$ 128$ bi em 2011. Valor Econômico, 31 jan. 2012. Disponível [apenas para assinantes] em: https://valor.globo.com/brasil/noticia/2012/01/31/pais-cumpre-meta-fiscal-e-faz-superavitprimario-de-r-128-bi-em-2011.ghtml. Acesso em: 12 jun. 2020.

KRUGMAN, Paul. Que diabos aconteceu com o Brasil? Não estou falando da recente eleição, mas sobre macroeconomia. Tradução de Paulo Migliacci. Folha de S. Paulo, 14 nov. 2018a. Disponível [apenas para assinantes] em: https://www1.folha.uol.com.br/colunas/paulkrugman/2018/11/que-diabos-aconteceu-como-brasil.shtml. Acesso em: 23 jun. 2020.

KRUGMAN, Paul. Que diabos aconteceu com o Brasil? Tradução de André Langer. Instituto Humanitas Unisinos - IHU, 15 nov. 2018b. Disponível em: http://www.ihu.unisinos.br/78noticias/584650-que-diabos-aconteceu-com-o-brasil. Acesso em: 23 jun. 2020.

MEDIDA Provisória $n^{\circ}$ 579/12 apresenta face interventora da Aneel: Agência passará a agir como operadora do sistema de distribuição de cotas de energia gerada por concessões vincendas. Energia Hoje, 4 out. 2012. Disponível em: https://energiahoje.editorabrasilenergia.com. br/artigo-medida-provisoria-n-57912apresenta-face-interventora-da-aneel/. Acesso em: 20 fev. 2019.

NASSIF, André; BRESSER-PEREIRA, Luiz Carlos; FEIJO, Carmem. The Case for Reindustrialisation in Developing Countries: Towards the Connection between the Macroeconomic Regime and the Industrial Policy in Brazil. Cambridge Journal of Economics, v. 42, n. 2, p. 355-381, Mar. 2018. https://doi.org/10.1093/cje/bex028

ROMERO, Cristiano. País mudou sua matriz econômica, diz Holland. Valor Econômico, 17 dez. 2012. Disponível em: https://valor.globo.com/brasil/coluna/pais-mudou-sua-matrizeconomica-diz-holland.ghtml. Acesso em: 11 fev. 2019.

SCRIVANO, Roberta. Real valoriza $108 \%$ frente ao dólar no governo Lula: estudo mostra que o Real foi a moeda que mais se valorizou em relação ao euro e outras 7 moedas da América Latina. O Estado de S. Paulo, 22 dez. 2010. Disponível em: https://economia.estadao.com.br/noticias/geral,real-valoriza-108-frente-ao-dolar-nogoverno-lula-imp-,657246. Acesso em: 3 jan. 2019.

SINGER, André. O lulismo em crise: um quebra-cabeça do período Dilma (2011-2016). São Paulo: Companhia das Letras, 2018.

SKAF, Paulo; HENRIQUE, Artur; SILVA, Paulo Pereira da. Um acordo pela indústria brasileira. Folha de S. Paulo - Opinião, 26 maio 2011. Disponível em: https://www1.folha.uol.com.br/fsp/opiniao/fz2605201107.htm. Acesso em: 12 nov. 2018. 
TABAK, Bernardo. Consumo das famílias teve pior resultado desde 2004, mostra IBGE: alta foi de 4,1\% no ano passado, segundo dados do PIB. G1 - Economia, 6 mar. 2012. Disponível em: http://glo.bo/ylE4iB. Acesso em: 12 jun. 2020. 